\title{
Service Quality in Iran's Medical Tourism: Hospitals in Shiraz City
}

\author{
Maryam Gholami $^{1}$, Alireza Jabbari ${ }^{2,3,}{ }^{\text {, }}$, Zahra Kavosi ${ }^{4}$, Marjan Gholami ${ }^{1}$ \\ ${ }^{1}$ Clinical Research Development Center, Shiraz University of Medical Sciences, Nemazee Hospital, Shiraz, IR Iran \\ ${ }^{2}$ Health Management and Economics Research Center, Isfahan University of Medical Sciences, Isfahan, IR Iran \\ ${ }^{3}$ Department of Health Services Management, Isfahan University of Medical Sciences, Isfahan, IR Iran \\ ${ }^{4}$ Department of Health Services Management, Shiraz University of Medical Sciences, Shiraz, IR Iran
}

*Corresponding Author: Alireza Jabbari, Assistant Professor of Health Care Management, Health Management and Economics Research Center, Isfahan University of Medical Sciences, Isfahan, Iran. Tel/Fax: 031-36684799, Email: jabbaria@mng.mui.ac.ir

\begin{abstract}
Introduction: Medical tourism is a main source of national income. Thus, evaluating the viewpoints of medical tourists about the quality of service provided by healthcare centers may be useful in planning to develop this industry. The present study aimed to measure the gap between medical tourists' expectations and perceptions of the quality of service offered by the hospitals in Shiraz using the SERVQUAL model.

Methods: This cross-sectional study was performed on 200 medical tourists referred to hospitals in the city of Shiraz which is located in the south of Iran. The subjects were selected randomly over the first 6 months of 2013. Data collection tools were a descriptive questionnaire and an adaptation of the SERVQUAL questionnaire.

Results: The results showed that the mean age of medical tourists was 49.67 and most of them were from Oman. Overall, the patients' expectations exceeded their perceptions of the provided quality of service, and all gap mean scores were negative. The largest negative gap score pertained to reliability with an overall average of -0.59 , followed by responsibility, assurance, tangibility, empathy, and access to care.

Conclusion: The research findings can effectively help managers identify problems with the current quality of service and improve performance so as to increase the medical tourists' satisfaction level. Also, highlighting the most important service attributes, which are highly attractive to patients, will help authorities improve their operation performance and develop innovative ideas on both strategic and tactical levels.

Keywords: Medical Tourism, Service Quality, Hospitals, Iran
\end{abstract}

Article History: Received: 8 Oct. 2015; Accepted: 1 Des. 2015; Online Published: 10 Apr. 2016

Cite this article as: Gholami M, Jabbari A, Kavosi Z, Gholami M. Service quality in Iran's medical tourism: hospitals in Shiraz city. Int J Travel Med Glob Health. 2016;4(1):19-24

\section{Introduction}

The travel, tourism, and hospitality industry is one of the main sources of global gross domestic product (GDP) and an important employment generator [1]. Most governments regard it as a guideline for the development of the country [2]. One new form of tourism that has gained huge popularity in recent decades is medical tourism [3], the act of traveling across international borders with the intention of receiving some form of medical treatment [4]. During the past years, patients traveled from developing countries to more developed countries to get medical services unavailable in their own countries. Today, people make international trips to developing countries to receive healthcare. Reasons for this phenomenon include long waiting lists in developed countries, low cost of medical treatment in developing countries, affordable cost of international transportation, development of the Internet, emergence of international communication companies which act as intermediaries between patients and hospital networks and make it easy for patients to access information and prices; and finally, advanced technologies which are new to healthcare services [5].

The low cost and high income possibility of the medical tourism industry has prompted many countries to plan to develop this section of the tourism industry [6]. In the Middle East, Iran is one of the main settings for health tourism due to its potentialities, such as expert physicians, up-to-date medical technology, and natural healing areas [7]. This has recently led to an increase in studies in the field of medical tourism [8-13].

In the south of Iran, Shiraz is a main destination of medical tourists. The reasons for this popularity are that Shiraz University of Medical Sciences is one of the most prestigious and type one universities in the country and even the world; public and private hospitals in Shiraz are equipped with modern devices and diagnostic and therapeutic equipment and are staffed with professors and experienced doctors. Moreover, this city's proximity to Arab countries in the Persian Gulf makes it a destination for the highest number of admitted medical tourists from these countries, especially Oman, and most of them receive ophthalmology surgical services [14-16].

Over the last three decades, service quality has been a controversial issue for researchers, and most of the research has focused on measuring this factor [17-21]. Researchers have addressed two important issues: (1) Which factors do customers consider in evaluating the quality of a service? and (2) How can one measure the quality of a service from the customer's perspective? [22].

Pre-service and post-service perceptions are two key issues in the customer's perception of the quality of service which depend on a set of factors called "dimensions of service quality." The difference between these two concepts is defined as the service quality gap, and is essential for identifying the aspects of service that need performance improvement, evaluating how much improvement is required, and assessing the impact of improvement efforts [23]. Introduced by Parasuraman, Zeithaml, and Berry, the SERVQUAL model is one of the most frequently used instruments for evaluating the service quality gap. This scale is designed in the form of a survey containing 22 service attributes grouped into five dimensions: reliability, responsiveness, assurance, empathy, and tangibles [20].

In healthcare research, the quality of care services from the patient's viewpoint has increasingly been measured [24-26]. In such studies, a patient is considered an active consumer of 
services rather than merely a passive recipient [27]. In their study, Lim et al. determined the expectations and perceptions of Singaporean patients through the use of a SERVQUAL instrument [28]. In another study, a reformed version of this tool was applied to assess patient satisfaction with health services in Bangladesh [29]. Peprah et al. used an adapted and modified SERVQUAL instrument to capture relevant data, and the gap scores were analyzed for individual statements and for each dimension [30].

Since appropriate quality of medical services is one of the most important reasons for medical travel, evaluating the quality of service from the medical tourists' perspective may be useful [31]. In Binti Ahmad et al.'s study, the efficacy of the medical tourists' expectations and perceptions of the service quality and a comprehensive scale, SERVQUAL, were surveyed in Malaysia [32]. Another study in India conducted on medical tourists highlighted the main requirements for delivering high quality service using the SERVQUAL model. It showed that the application of this model enables a hospital engaged in medical tourism to provide superior quality service resulting in customer satisfaction amidst the competition [33]. Moreover, Guiry et al. used the SERVQUAL scale to assess U.S. medical tourists' expectations and perceptions of the quality of service in healthcare facilities located outside the United States [34]. More studies have also focused on patient viewpoints of medical performance using this instrument [24, 34, 35].

The impact of the medical tourism industry on increasing revenues makes evaluating the service quality gap between medical tourists' expectations and perceptions seem helpful. Therefore, this study aimed to identify the service quality gap of medical tourists referred to Shiraz hospitals using the SERVQUAL model.

\section{Methods}

This study was a cross-sectional survey conducted on medical tourists from countries bordering the Persian Gulf who were referred to private hospitals in Shiraz (including Ordibehesht, Doctor Khodadoust, Pars, Madar and Koudak, Markazi [MRI], and Dena hospitals).

This project was confirmed by the Ethics Committee and the Research Council of Isfahan University of Medical Sciences. The only inclusion criteria was the informed consent of medical tourists to participate in the study. Data was collected over the first 6 months of 2013 through simple random sampling. It should be noted that public and other private hospitals in the city were excluded due to their low number (if any) of medical tourists (at least $<10$ patients each month).

In the present study, two questionnaires were used. The first one contained 14 descriptive questions regarding age, sex, marital status, education level, place of residence of the patients and his companions, nationality, type of travel to Iran and Shiraz, source of information which the patients achieved from the selected hospitals, type of medical treatment demanded by patients, and length of stay in the city and hospital; all this data was collected upon admission.

The second one was a modified version of the SERVQUAL instrument used to determine the gap between medical tourists' expectations and perceptions of the quality of service provided by the selected hospitals. This instrument contained 22 items grouped into the six dimensions of tangibles, reliability, responsiveness, assurance, empathy, and access to care that were measured on a five-point scale with (1) indicating 'very low' and (5) 'very high'. For ease of completion, both questionnaires were translated into Arabic and English. In English, two separate questionnaires existed for the SERVQUAL model to appraise the patients' expectations and perceptions. As both of them were the same in the content and number of questions, but in Arabic, these questionnaires were the same. The SERVQUAL instrument's validity was confirmed by experts. To evaluate its reliability, the researchers randomly selected 30 medical tourists in a pilot study. After explaining the objectives and purpose of the study, they tried to get valuable feedback from the patients. The reliability was confirmed by Cronbach's Alpha test (92.6\%).

The patients' descriptive information and their "expectations" from the hospital service were gathered upon admission using the questionnaires. Then on the day they were discharged from the hospital, the researcher asked their perceptions of the service. Finally, the gathered data was analyzed using SPSS software version 16.0.

\section{Results}

Due to the limited number of medical tourists and a lack of cooperation from a large number of them, only 200 questionnaires were completed by medical tourists who referred to selected hospitals during the 6-month study period; most of those patients (70) referred to Dr. Khodadoost hospital.

A part of the descriptive statistics results are shown in Table 1. As can be seen, $128(64 \%)$ patients were male and $72(36 \%)$ were female. Mean age was $49.66 \pm 16.04$, and minimum and maximum ages were 1 year and 97 years, respectively; $154(77 \%)$ patients were married, $20(10 \%)$ were single, $12(6 \%)$ were divorced, and $14(7 \%)$ were widowed. Educational status and type of therapeutic service that patients received are also reported in Table 1 . The findings also showed that $160(80 \%)$ patients were from Oman, Kuwait, and Iraq, 101 of whom (50.5\%) came from Oman. To access the detailed descriptive information, refer to Jabbari et al.'s study [14].

\begin{tabular}{lcc}
\multicolumn{3}{c}{ Table 1. Demographic data $(\mathrm{n}=200)$} \\
\hline Variable & M & (\%) \\
\hline \multirow{2}{*}{ Gender } & Female & $128(64)$ \\
& Married & $72(36)$ \\
& Single & $154(77)$ \\
\multirow{2}{*}{ Marital status } & Divorced & $12(10)$ \\
& Widowed & $14(7)$ \\
\multirow{2}{*}{ Education } & Low literate & $115(57.5)$ \\
& High school diploma & $85(42.5)$ \\
\multirow{2}{*}{ Type of therapeutic service } & Eye & $132(66)$ \\
& Plastic surgery & $28(14)$ \\
& General & $29(14.5)$ \\
& Fertility and infertility & $11(5.5)$ \\
\hline
\end{tabular}

Paired T-tests were carried out to determine any significant differences between the two means of expectations and perceptions regarding the quality of service offered by the hospitals. Table 2 shows the means, difference scores, $\mathrm{T}$ value, and significance obtained through the evaluation of each service quality dimension. In this table, the gap mean score for each dimension was calculated by subtracting the perception mean from the expectation mean. A positive mean score shows good expected service, while a negative one shows poor quality service. Although all resulting mean 
scores for expectation and perception were greater than 4 and this indicates a good quality of service provided for patients, the resulting gap mean values for all dimensions were negative, thus revealing the poor service quality in the patient's viewpoint as compared with their expectations. This difference can be observed easily in Figure 1. This figure is a radar chart generated based on the mean scores of SERVQUAL dimensions. In this chart, hexagonal vertices represent the dimensions, and the distance between the line and the dash represents the gap between the means of expectations and perceptions.

All differences were statistically significant except the value related to the sixth dimension, access to care. The biggest gap was related to reliability, which shows that medical tourists were very dissatisfied with the reliability offered by the hospitals. The second dissatisfaction attribute is related to responsibility.

Table 2. The means, difference scores, T value, and significance obtained through the evaluation of each service quality dimension

\begin{tabular}{|c|c|c|c|c|c|}
\hline DIMENSION & Mean (SD) Expectation & Mean (SD) Perception & Mean (SD) Gap & T value & p-value \\
\hline Tangibility & $4.5(0.41)$ & $4.21(0.55)$ & $-0.3(0.51)$ & -7.321 & $<0.001$ \\
\hline Reliability & $4.81(0.38)$ & $4.21(0.65)$ & $-0.59(0.65)$ & -10.049 & $<0.001$ \\
\hline Responsibility & $4.8(0.38)$ & $4.29(0.64)$ & $-0.51(0.62)$ & -9.489 & $<0.001$ \\
\hline Assurance & $4.77(0.37)$ & $4.41(0.58)$ & $-0.36(0.55)$ & -8.396 & $<0.001$ \\
\hline Empathy & $4.61(0.44)$ & $4.39(0.54)$ & $-0.22(0.54)$ & -6.466 & $<0.001$ \\
\hline Access to Care & $4.54(0.57)$ & $4.46(0.65)$ & $-0.08(0.69)$ & -1.657 & 0.098 \\
\hline
\end{tabular}

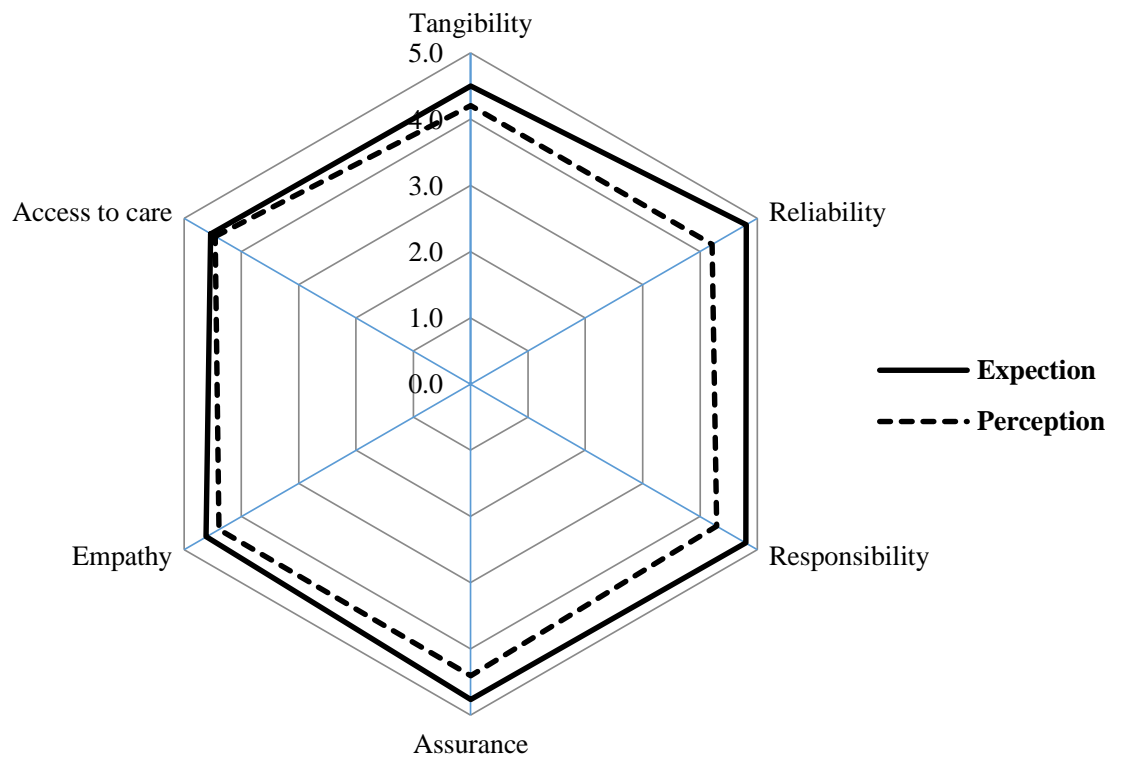

Figure 1. Expectation - Perception Gap Analysis (SERVQUAL dimensions)

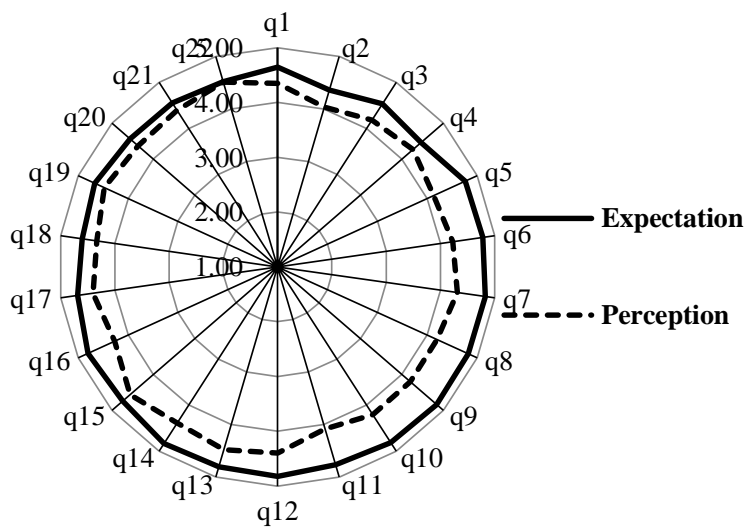

Figure 2. Expectation - Perception Gap Analysis (SERVQUAL questions)

Table 3 shows the means, difference scores, $\mathrm{T}$ value, and significance obtained through the evaluation of each question related to each dimension. As seen in this table, all expectation and perception means were greater than 4 , but the resulting gap means for all questions were negative. Moreover, this table shows that the biggest gap was related to providing prompt service. This difference can be observed easily in Figure 2.
Figure 3 indicates the scatter plot of perception versus expectation means for all subjects under study. Two vertical and horizontal lines were drawn based on overall expectation and perception means, respectively; as shown, the overall mean of expectation was more than that of perception (4.7 vs. 4.3). As also seen in this figure, most case scores were set above 4; this reflects the patients' perspective of high quality of service. 
Table 3. The means, difference scores, $T$ value and significance obtained through the evaluation of each question

\begin{tabular}{|c|c|c|c|c|c|c|}
\hline Dimension & Variables & $\begin{array}{c}\text { Mean(SD) } \\
\text { Expectation }\end{array}$ & $\begin{array}{l}\text { Mean(SD) } \\
\text { Perception }\end{array}$ & $\begin{array}{l}\text { Mean (SD) } \\
\text { Gap }\end{array}$ & t value & p-value \\
\hline \multirow{4}{*}{ Tangibility } & Up-to-date medical equipment & $4.65(0.59)$ & $4.35(0.82)$ & $-0.3(0.85)$ & -4.98 & $<0.001$ \\
\hline & Visually appealing physical facilities & $4.37(0.57)$ & $4.04(0.8)$ & $-0.33(0.76)$ & -6.16 & $<0.001$ \\
\hline & Doctors and staffs are neat in appearance & $4.54(0.62)$ & $4.18(0.81)$ & $-0.36(0.81)$ & -6.21 & $<0.001$ \\
\hline & $\begin{array}{l}\text { Visually appealing facilities associated with hospital } \\
\text { service }\end{array}$ & $4.47(0.55)$ & $4.27(0.77)$ & $-0.2(79)$ & -3.47 & 0.001 \\
\hline & Tangibility Score & $4.5(0.41)$ & 4.21(0.55) & $-0.38(0.44)$ & -7.321 & $<0.001$ \\
\hline \multirow{5}{*}{ Reliability } & Proper and on time services & $4.76(0.57)$ & $4.13(0.97)$ & $-0.63(0.96)$ & -9.25 & $<0.001$ \\
\hline & $\begin{array}{l}\text { Sympathy and reassurance to patients when they face } \\
\text { problems }\end{array}$ & $4.78(0.48)$ & $4.23(0.91)$ & $-0.56(0.85)$ & -9.18 & $<0.001$ \\
\hline & $\begin{array}{l}\text { Building trust and giving correct information about the } \\
\text { process and services to patients by staffs }\end{array}$ & $4.83(0.46)$ & $4.32(0.82)$ & $-0.51(0.8)$ & -9.065 & $<0.001$ \\
\hline & Provision of services at the time they promise to do so & $4.82(0.48)$ & $4.2(1.02)$ & $-0.63(0.99)$ & -8.932 & $<0.001$ \\
\hline & Keeping the patient records accurately & $4.84(0.42)$ & $4.2(0.91)$ & $-0.64(0.95)$ & -9.515 & $<0.001$ \\
\hline \multicolumn{2}{|r|}{ Reliability Score } & 4.81(0.38) & $4.21(0.65)$ & $-0.3(0.51)$ & -10.049 & $<0.001$ \\
\hline \multirow{4}{*}{ Responsibility } & $\begin{array}{l}\text { Telling the patients exactly when services will be } \\
\text { performed }\end{array}$ & $4.81(0.52)$ & $4.21(0.91)$ & $-0.61(0.96)$ & -8.903 & $<0.001$ \\
\hline & Continuous willingness to help patients by staff members & $4.83(0.42)$ & $4.4(0.8)$ & $-0.43(0.82)$ & -7.438 & $<0.001$ \\
\hline & Providing the patient with requested services promptly & $4.81(0.48)$ & $4.48(0.76)$ & $-0.33(0.8)$ & -5.86 & $<0.001$ \\
\hline & Responsibility Score & 4.8(0.38) & $4.29(0.64)$ & $-0.59(0.65)$ & -9.489 & $<0.001$ \\
\hline \multirow{4}{*}{ Assurance } & $\begin{array}{l}\text { The effect of doctor and staff behavior on patients' } \\
\text { confidence }\end{array}$ & $4.84(0.46)$ & $4.39(0.88)$ & $-0.45(0.91)$ & -6.978 & $<0.001$ \\
\hline & Feeling safe in the payment to the hospital by patient & $4.74(0.51)$ & $4.57(0.68)$ & $-0.18(0.67)$ & -3.703 & $<0.001$ \\
\hline & Polite behavior with patients & $4.8(0.45)$ & $4.27(0.81)$ & $-0.53(0.79)$ & -9.502 & $<0.001$ \\
\hline & $\begin{array}{l}\text { Knowledge and expertise of personnel in response to } \\
\text { patient questions }\end{array}$ & $4.69(0.63)$ & $4.4(0.76)$ & $-0.29(0.83)$ & -4.862 & $<0.001$ \\
\hline & Assurance Score & 4.77(0.37) & 4.41(0.58) & $-0.51(0.62)$ & -8.396 & $<0.001$ \\
\hline \multirow{3}{*}{ Empathy } & Giving individual attention to the patient & $4.6(0.62)$ & $4.34(0.76)$ & $-0.27(0.76)$ & -4.931 & $<0.001$ \\
\hline & $\begin{array}{l}\text { Giving personal attention to patients' real needs and } \\
\text { showing interest to them }\end{array}$ & $4.67(0.57)$ & $4.48(0.71)$ & $-0.19(0.62)$ & -4.326 & $<0.001$ \\
\hline & $\begin{array}{l}\text { Listening to the opinions of patients and keeping them } \\
\text { apprised }\end{array}$ & $4.57(0.6)$ & $4.37(0.67)$ & $-0.2(0.71)$ & -3.99 & $<0.001$ \\
\hline Access to care & Empathy Score & 4.61(0.44) & $4.39(0.54)$ & $-0.36(0.55)$ & -6.466 & $<0.001$ \\
\hline
\end{tabular}

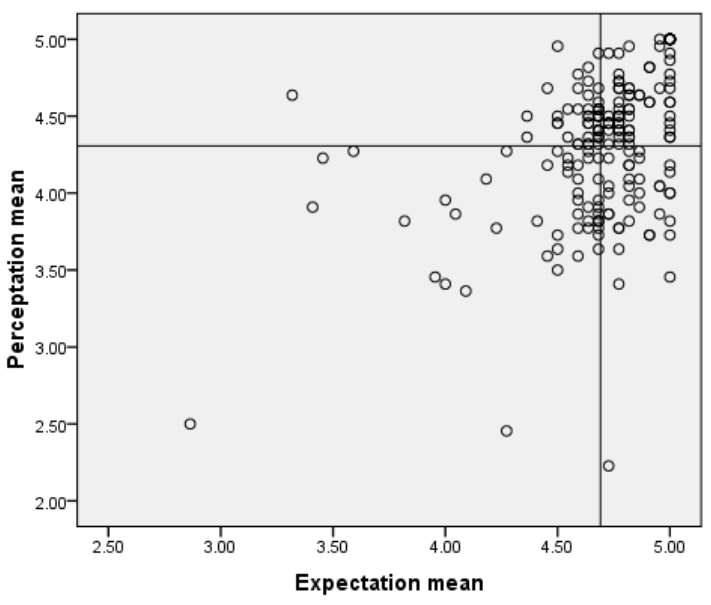

Figure 3. Scatter plot for perception mean vs. expectation mean for all cases

\section{Discussion}

The medical tourism industry provides new additional financial resources to the healthcare system of every country. One important factor in attracting medical tourists is increasing the level of service quality in hospitals. Studies which research the gap between patients' expectations and perceptions can aid managers in identifying the sources of problems in quality and ways to promote satisfaction levels. In the present study, 200 medical tourists were evaluated. The mean age of the patients was nearly 50 years, and most of them were married. The findings showed that most of them were from Oman, and the top reason for their referral was professional ophthalmology services.

The main objective of this research was to measure the difference between expectations and perceptions of medical tourists referred to Shiraz hospitals by using the SERVQUAL gap score introduced by Parasuraman et al. $[18,19]$ to identify problems and evaluate the level of service quality.

According to the results, all gap mean scores were negative, indicating that the patients expected a better quality of service than what the hospitals offered. The dimension with the largest negative gap score was reliability with an overall average of -0.59 , followed by the dimensions of responsibility, assurance, tangibility, empathy, and access to care.

A study of U.S. consumers who traveled abroad for medical care showed that reliability had the largest service quality gap between U.S. medical tourists' perceived level of service provided and their expectations, which is inconsistent with the results of the present study [34].

Karassavidou et al. evaluated patient perceptions and expectations of service quality in NHS hospitals located in North Greece. This empirical research revealed that patients' expectations exceeded their perceptions of the provided service quality, which is consistent with the findings of the current study. The researchers concluded that SERVQUAL can be considered a flexible tool, because it allows them to incorporate the idiosyncrasies of a specific industry and/or national context [36]. 
Wong et al. used the SERVQUAL instrument to study the quality of service provided for ambulatory clients at the Bone Densitometry Unit in Royal Brisbane Hospital. According to their results, the dimensions of responsiveness, assurance and empathy were more important predictors of overall service satisfaction. Perception scores better predicted overall satisfaction than gap scores [37].

In another study, the SERVQUAL instrument was used to compare the service quality provided in public and private hospitals in Northern Cyprus. Based on analysis, private hospitals had smaller gaps than public hospitals in all service quality dimensions. In addition, reliability, empathy and tangibles were influential factors on patient satisfaction [38]. Still other studies have indicated that quality of service, from the patient's perspective, requires that the medical staff show respect, empathy, and concern in addition to having some traditional items like professional skill. Observing these factors makes patients trust and rely on a hospital more and continue to refer there for future medical treatments [39-41].

\section{Conclusion}

Using perceived service quality provides healthcare businesses with a deep understanding of their service quality levels from their patients' perspective. Highlighting the most important service attributes, which are highly attractive for patients, helps management improve their operational performance and develop innovative ideas on both strategic and tactical levels.

The results of the current study suggest that the managers of the studied hospitals should re-evaluate their strategies on giving more reliability and responsibility to their patients, because these two dimensions can significantly affect the satisfaction levels of medical tourists. Promoting these two attributes can lead to improvement in other attributes as well, because a defect and gap in a dimension causes a drop in quality in other aspects of service from the patients' perspective.

Data analysis suggested that, to reduce the gap in reliability, hospital management can instigate policies giving medical tourists further information about the knowledge, skills, and abilities of doctors and nurses. This strategy would make patients more confident in the hospital staff. In addition to increasing staff responsibility, authorities should encourage their staff to respect patient requests and deliver prompt service while showing interest.

This study had some limitations. First, the process of completing questionnaires at two different times caused some patients to refuse to answer the questions on admission or discharge. Moreover, to complete the questionnaires, it was necessary to get permission from all relevant authorities in the healthcare centers. The medical tourism industry was new in the city and some managers were unfamiliar with it. Lack of appropriate cooperation from some managers was another limitation.

This research can be extended into a study to evaluate the quality of service in all public and private hospitals in the country that provide services to medical tourists. Moreover, a study which compares the quality of services in the view of internal patients and medical tourists may be useful.

\section{Acknowledgments}

The authors express their appreciation to the ViceChancellery of Shiraz University of Medical Sciences, Shiraz, Iran, and to the Center for Development of Clinical
Research of Nemazee Hospital. The authors also thank Parisa Chamanpara for her statistical assistance and Dr. Nasrin Shokrpour for her editorial assistance.

\section{Authors' Contributions}

All authors contributed equally in the preparation of this paper.

\section{Financial Disclosure}

Not declared.

\section{Funding/Support}

This research has been supported by Isfahan University of Medical Sciences.

\section{References}

1. Ayoubian A, Tourani S, Hashemi Dehaghi Z. Medical tourism attraction of Tehran hospitals. Int $\mathrm{J}$ Travel Med Glob Health. 2013;1(2):95-8

2. Hall CM. Introduction to tourism: development, dimensions and issues: Longman; 1998.

3. Caballero-Danell S, Mugomba C. Medical tourism and its entrepreneurial opportunities: A conceptual framework for entry into the industry. 2007.

4. Lunt N. Medical tourism: treatments, markets and health system implications: a scoping review: OECD, Directorate for Employment, Labour and Social Affairs; 2011.

5. Piazolo M, Zanca NA. The economics of medical tourism a case study for the USA and India. Óbuda University, Keleti Faculty of Economics, India. 2010.

6. Kazemi Z. Study of effective factors for attracting medical tourist in Iran. Research paper requirements for the MS degree, Lulea University of Technology, Netherlands. 2007.

7. Izadi M, Ayoobian A, Nasiri T, Joneidi N, Fazel M, Hosseinpourfard M. Situation of health tourism in Iran; opportunity or threat. Mil Med J. 2012;14(2):69-75.

8. Jabbari A, Ferdosi M, Keyvanara M, Agharahimi Z. Stakeholders' analysis of the medical tourism industry: development strategies in Isfahan. J Educ Health Promot. 2013;2.

9. Jabbari A, Najar A, Nezamdoost F, Ebrahimipour H. Are Mashhad hospitals ready for medical tourists? Int J Health System Disaster Manag. 2014;2(3):170.

10. Jabbari A, Agharahimi Z, Hosseini S, Safari F. Capabilities of infertility tourism in Isfahan: A qualitative study 1 . Int $\mathbf{J}$ Health System Disaster Manag. 2013;1(2):99.

11. Masoud F, Alireza J, Mahmoud K, Zahra A. A systematic review of publications studies on medical tourism. J Educ Health Promot. 2013;2.

12. Zarchi MR, Jabbari A, Rahimi SH, Shafaghat T, Abbasi S. Preparation and Designing a Checklist for Health Care Marketing Mix, with Medical Tourism Approach. Int J Travle Med Glob Health. 2014;1(3):103-8.

13. Jabbari A, Delgoshaei B, Mardani R, Tabibi SJ. Medical tourism in Iran: Issues and challenges. J Educ Health Promot. 2012;1.

14. Jabbari A, Kavosi Z, Gholami M. Medical tourists' profile in Shiraz. Int J Health System Disaster Manag. 2014;2(4):232.

15. Rokni L, Pourahmad A, Langroudi MHM, Mahmoudi MR, Heidarzadeh N. Appraisal the potential of central Iran, in the context of health tourism. Iran J Public Health. 2013;42(3):272.

16. Jabbari A, Zarchi MKR, Kavosi Z, Shafaghat T, Keshtkaran A. The marketing mix and development of medical tourism in Shiraz. Mater Sociomed. 2013;25(1):32.

17. Cronin Jr JJ, Taylor SA. Measuring service quality: a reexamination and extension. J Mark. 1992:55-68.

18. Parasuraman A, Berry LL, Zeithaml VA. Understanding customer expectations of service. Sloan Manag Rev. 1991;32(3):39-48.

19. Parasuraman A, Zeithaml VA, Berry LL. A conceptual model of service quality and its implications for future research. J Mark. 1985:41-50.

20. Parasuraman A, Zeithaml VA, Berry LL. Servqual: A Multiple-Item Scale for Measuring Consumer Perceptions of Service Quality dalam Journal of Retailing. J Retailing. 1988;64(1):12-39.

21. Zeithaml VA, Berry LL, Parasuraman A. The nature and determinants of customer expectations of service. J Aca Mark Sci. $1993 ; 21(1): 1-12$. 
22. Seth N, Deshmukh S, Vrat P. Service quality models: a review. Int J Quality Reliability Manag. 2005;22(9):913-49.

23. Zeithaml VA, Bitner MJ, Gremler DD. Services marketing: Integrating customer focus across the firm. 2006.

24. Lin H-C, Xirasagar S, Laditka JN. Patient perceptions of service quality in group versus solo practice clinics. Int J Qual Health Care. 2004;16(6):437-45.

25. Rao KD, Peters DH, Bandeen-Roche K. Towards patient-centered health services in India - a scale to measure patient perceptions of quality. Int J Qual Health Care. 2006;18(6):414-21.

26. Van Duong D, Binns CW, Lee AH, Hipgrave DB. Measuring clientperceived quality of maternity services in rural Vietnam. Int $\mathrm{J}$ Qual Health Care. 2004;16(6):447-52.

27. Speight J. Assessing patient satisfaction: concepts, applications, and measurement. Value Health. 2005;8(s1):S6-S8.

28. Cheng Lim P, Tang NK. A study of patients' expectations and satisfaction in Singapore hospitals. Int J Health Care Qual Assur. 2000;13(7):290-9.

29. Andaleeb SS, Siddiqui N, Khandakar S. Patient satisfaction with health services in Bangladesh. Health Policy Plan. 2007;22(4):26373.

30. Peprah AA, Atarah BA. Assessing Patient's Satisfaction using SERVQUAL Model: A Case of Sunyani Regional Hospital, Ghana. Int J Bus Soc Res. 2014;4(2):133-43.

31. Shaarbafchizadeh N, Tourani S, Abolhassani N, Bastani P, Aazami S. Medical Tourism industry; Challenges and Opportunities. Jökull Journal. 2013;63(10):119-33.
32. Ahmad ZB, Yusuf WZBW, Sidi NSBS. Johor's Potential as Medical Tourist Destination: Measurement of Service Quality used Medical Tourism (MT)-SERVQUAL. 2014.

33. Udupa AR, Kotreshwar G. Implications of Service Quality Model for Medical tourism in India. Asian J Manag. 2010;1(2):65-8.

34. Guiry M, Vequist DG. Traveling abroad for medical care: US medical tourists' expectations and perceptions of service quality. Health Mark Q. 2011;28(3):253-69.

35. Cho WH, Lee H, Kim C, Lee S, Choi KS. The impact of visit frequency on the relationship between service quality and outpatient satisfaction: a South Korean study. Health Serv Res. 2004;39(1):13 34.

36. Karassavidou E, Glaveli N, Papadopoulos CT. Health Care Quality in Greek NHS Hospitals: No one knows better than patients. 2008.

37. Wong JC. Service quality measurement in a medical imaging department. Int J Health Care Qual Assur. 2002;15(5):206-12.

38. Yeşilada F, Direktör E. Health care service quality: A comparison of public and private hospitals. Afr J Bus Manag. 2010;4(6):962-71.

39. Amin M, Zahora Nasharuddin S. Hospital service quality and its effects on patient satisfaction and behavioural intention. Clinical Governance: An International Journal. 2013;18(3):238-54.

40. Tang C, Luo Z, Fang P, Zhang F. Do patients choose community health services (CHS) for first treatment in China? Results from a community health survey in urban areas. J Community Health. 2013;38(5):864-72.

41. You L-m, Aiken LH, Sloane DM, Liu K, He G-p, Hu Y, et al. Hospital nursing, care quality, and patient satisfaction: crosssectional surveys of nurses and patients in hospitals in China and Europe. Int J Nurs Stud. 2013;50(2):154-61. 